\title{
Transient Stability Improvement of a FSIG Based Grid Connected wind Farm with the help of a SVC and a STATCOM: A Comparison
}

\author{
Rajiv Singh, Asheesh Kumar Singh, and Ashutosh Kumar Singh
}

\begin{abstract}
The contribution of wind power in conventional generation is increasing rapidly now-a-days. Hence a better understanding of wind power plants is required. But the wind power plants generally containing induction generators exhibit a rather different behavior than the conventional power plants which use synchronous generators. The purpose of this paper is to analyze and study transient stability of a wind farm based on conventional fixed speed Induction generator when it has been integrated with a weak grid. A comparative analysis of the transient stability improvement of a FSIG wind plant has been done, when it is supported with FACTS like S.V.C and STATCOM of equal ratings. Single case of transient condition i.e. a three phase fault has been studied by simulation.
\end{abstract}

Index Terms - Wind farm, weak grids, fixed speed induction generator (the squirrel cage induction generator), S.V.C, STATCOM.

\section{INTRODUCTION}

With the increase in demand of power and decrease of fossil fuels, mankind has been forced to search alternative sources for the generation of electricity. Wind power in spite of being stochastic in nature has proved itself as a viable solution to this problem. As the wind turbine technology is developing at a good pace, more and more wind power plants are being integrated with the conventional form of generation. With the increase in the ratio of wind generation to conventional generation, several problems related with integration of wind farms have emerged. These problems are due to distinct properties of the generators used with the conventional form (Thermal \& Hydro) of generation and wind based generation [1]-[4]. In thermal and hydro power based generation synchronous generators are used while in wind based generation mostly induction generators are used. Induction and synchronous generators do not exhibit similar behavior during power system stresses (transients). Moreover, increase in wind power based generation requires a reliable transmission system for power evacuation to the load centers. As the wind farms are mainly concentrated in far flung and rural areas their interconnection with the grid becomes a problem. This problem is mainly due to the existence weak transmission grids in the rural areas [1]-[4]. Earlier when the

Manuscript received October 5, 2011; revised December 31, 2011.

Rajiv Singh and Asheesh Kumar Singh are with the department of Electrical Engineering, MNNIT, Allahabad, U.P, India (e-mail:rajiv77singh@gmail.com).

Ashutosh Kumar Singh is with Electronics and Comm. Engg. Deptt., Indian Institute of Information Technology, Allahabad ,India.(e-mail: ashutosh_mnnit1@rediffmail.com) share of wind power generation as compared with the conventional generation was low, during transient conditions; whenever the power system reached on the verge of instability the wind farm was disconnected from the grid and was reconnected when transients passed away. But as the share of wind power in the conventional generation increased, the practice of disconnecting the wind farms from the rest of the grid led to the drop in frequency of the power system. So now-a- days even if a fault occurs in the power system somewhere near the wind farms, they still remain connected with the grid for a critical time period. This phenomenon is called fault ride through (FRT) in wind farms [5]. This paper has studied a transient condition (fault) in a grid connected fixed speed induction generator based wind farm and its fault ride through performance. A comparison of the performance of fact devices like static var compensators (svc) and static synchronous compensators (statcom) in improving the transient stability of wind farms during fault is also done.

\section{POWER System Stability CONCEPTS}

There are mainly three concepts of power system stability universally accepted in conventional power system definitions. These are described as follows:

(a) Voltage Stability - when a power system is able to maintain a constant steady state voltage at every bus even after it has been subjected to small disturbances from the initial operating conditions, it is said to have attained voltage stability. So voltage stability in a power system is achieved when there exists equilibrium between the load demand and load supply [6]-[8].

(b) Rotor angle stability-when all the synchronous machines in a power system runs in synchronism with each other even after being subjected to a disturbance, the power system is said to possess rotor angle stability [6]-[8].

(c) Frequency Stability-whenever there is a gap in the load demand and generation in a power system its operating frequency drops. So a power system which is capable of maintaining a constant system frequency during such conditions is said to possess frequency stability [6]-[8].

The description of power system stability in terms of the above three parameters (Voltage, frequency and rotor angle) is relevant in a conventional power system which is fed only by Synchronous generators. But if a power system is interconnected with a FSIG based wind farm another concept called 'rotor speed stability' in addition to the above concepts comes into picture [6]-[8].

(d) The 'rotor speed stability' of a FSIG based wind farm is defined as the ability of FSIG based wind generators to 
maintain a fixed mechanical speed which is near to the speed corresponding to the actual power system frequency even if it is subjected to a disturbance [6]-[8].

\section{POWER SYSTEM DESCRIPTION}

The general layout of a power system which was simulated for study of transient stability is drawn in fig. 1 below. The simulations were carried out by power system modeling tool called SIMPOWER SYSTEM in the SIMULINK environment of MATLAB software. The power system consists of a wind farm containing 40 units of 1.5 MVA, FSIG based wind turbines, and the induction generator connected with the turbine operates at a power factor of 0.9 . For reactive power compensation a shunt capacitor has been connected at the generator terminals. Two step-up transformers of 60 MVA have been connected between the wind farm and rest of the grid. A $70 \mathrm{~km}$ transmission line connects the $60 \mathrm{MVA}$ wind farm transformer with the rest of grid.

The main transmission grid is simulated by a three-phase balanced a.c. voltage source, having the short circuit power of $2500 \mathrm{MVA}$ and the short circuit ratio (X/R) of 15 at 132 $\mathrm{KV}$ voltages. The active voltage/var regulator devices like STATCOM, SVC are connected at the point of common coupling (PCC), i.e. at the bus B1 between 60 MVA Transformer and the $132 \mathrm{KV}$ transmission line connecting the main grid. The wind farm is represented aggregately as 40 units of $1.5 \mathrm{MVA}$ at 0.9 p.f. installed at one place. The total active power injected in the power system by the wind farm is approx. 66.66 MW. The wind generator consists of a wind turbine coupled with a induction generator (Squirrel-cage type).

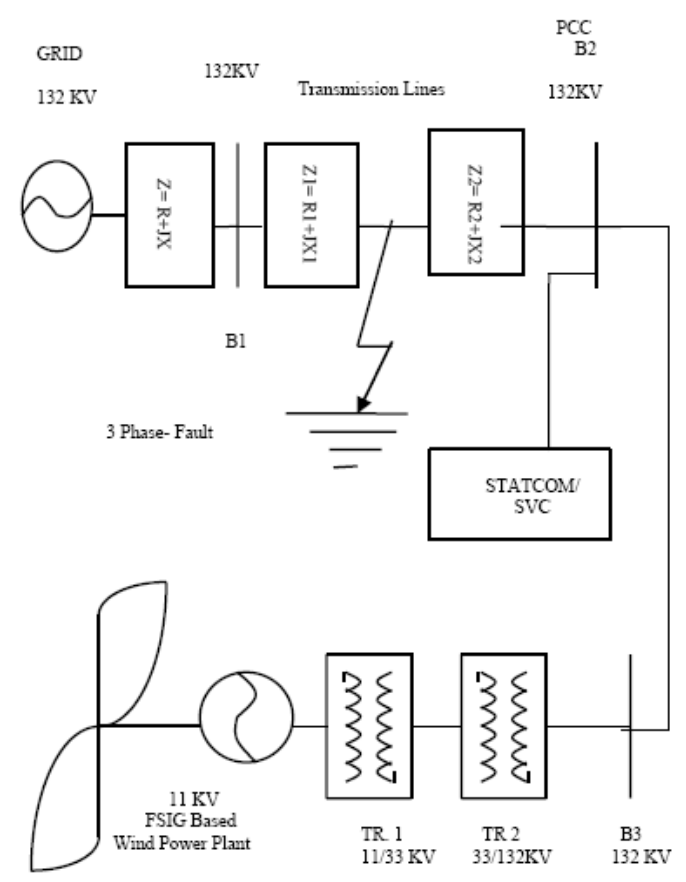

Fig. 1. Power system with FACTS.

The wind turbine model used is a variable pitch turbine but for the given case it is run at a constant pitch of 0 degrees to obtain the torque of 1 p.u. of the rated turbine power at a base wind speed of $9 \mathrm{~m} / \mathrm{s}$. The stiffness of the drive train is considered to be infinite and the Inertia and friction factor is considered together with the generator to which it is coupled. The wind turbine is coupled with an induction generator squirrel cage type. The stator of generator is connected with the grid directly and rotor is driven by the wind turbine. The wind power captured by the turbine is converted into electrical power by the induction generator and is transmitted to the grid through the stator windings.

The pitch angle of turbine is fixed or in a way the pitch angle control has been disabled to run it at a constant mechanical power output. In order to generate power the generator rotor speed must be slightly higher than its synchronous speed. Since the speed variation of squirrel cage wind generator is very less hence they are called fixed speed wind generators. The reactive power absorbed by the induction generator during transients is provided by the grid or by some devices like capacitor banks, SVC \& STATCOM.

The detailed parameters of the devices connected in the power system are given in the appendix.

\section{Mathematical Modelling OF A Few Power System COMPONENTS}

\section{A. Wind Turbine Model}

The model of wind turbine used for the purpose of simulation is a per unit model based on the steady state power equation of a wind turbine. The gear train used for coupling the generator with the grid is assumed to have infinite stiffness while the friction factor component and the inertia of the turbine is aggregated with these quantities of the electric generator coupled with the turbine [7]-[9].

$$
P_{m=} c_{p}(\lambda \beta) \rho A v_{\text {wind }}^{3}
$$

Here $P_{m}=$ mechanical power developed by the wind turbine,

$C_{p}=$ power coefficient of the turbine, $\rho$ is the density of air striking the turbine blades $\left(\mathrm{kg} / \mathrm{m}^{3}, \mathrm{~A}\right.$ is the swept area of the rotor blades of the turbine $\left(\mathrm{m}^{2}\right), \lambda$ is the tip-speed ratio, $\beta$ is the pitch angle (degrees).

\section{B. Electric Generator Model}

The electrical part of the generator has been modeled by the fourth order state space model while the mechanical part has been modeled by a second order system. The electrical parameters and variables have been referred on the stator side. All the stator and rotor quantities are in two axis d-q reference frame [7]-[9]. The dynamic equations are given as below:

For electrical system

$$
\begin{gathered}
V q s=\Omega s I q s+\frac{d \psi q s}{d t}+\omega \psi d s \\
V d s=\Omega s I d s+\frac{d \psi d s}{d t}-\omega \psi q s \\
V^{\prime} q r=\Omega^{\prime} r I^{\prime} q r+\frac{d \psi^{\prime} q r}{d t}+(\omega-\omega r) \psi^{\prime} d r \\
V^{\prime} d r=\Omega^{\prime} r I^{\prime} d r+\frac{d \psi^{\prime} d r}{d t}-(\omega-\omega r) \psi^{\prime} q r \\
\text { Telect. }=1.5 P(\psi d s I q s-\psi q s I d s)
\end{gathered}
$$

where

$$
\begin{aligned}
& \psi q q=L s I q s+L m I^{\prime} q r \\
& \psi d s=L s I d s+L m I^{\prime} d r \\
& \psi^{\prime} q r=L^{\prime} r I^{\prime} q r+L m I q s
\end{aligned}
$$




$$
\begin{gathered}
\psi^{\prime} d r=L^{\prime} r I^{\prime} d r+L m I d s \\
L s=L l s+L m \\
L^{\prime} r=L^{\prime} l r+L m
\end{gathered}
$$

The mechanical system is given by equations

$$
\begin{gathered}
\frac{d \omega m}{d t}=\frac{1}{2 H}(\text { Telect. }-F \omega m-T m) \\
\frac{d \theta m}{d t}=\omega m
\end{gathered}
$$

The machine parameters used for modeling are given as follows $\Omega s \& L l s$ are the stator resistance and leakage inductance, $\Omega^{\prime} r \& L^{\prime} l s$ are rotor resistance \& leakage inductance, $L m$ is magnetizing reactance, $L s \& L^{\prime} r$ are total stator \& rotor inductances, Vqs \& Iqs are q-axis stator voltage \& current, $V^{\prime} q r \& I^{\prime} q r$ are q-axis rotor voltage \& currents, $V d s \& I d s$ are d-axis stator voltage \& current, $V^{\prime} d r$ $\& I^{\prime} d r$ are d-axis rotor voltage \& currents, $\psi q s \& \psi d s$ are $\mathrm{q}$ $\& \mathrm{~d}$ axis stator fluxes, $\psi^{\prime} q r \& \psi^{\prime} d r$ are rotor $\mathrm{q} \& \mathrm{~d}$ axis fluxes, $\omega m$ is the angular velocity of rotor, $P$ is the no. of poles, $\omega r$ is the electrical angular velocity, Telect. is the electromagnetic torque, $\mathrm{Tm}$ is the shaft mechanical torque, $\mathrm{j}$ is the combined generator \& turbine inertia coefficient, $\mathrm{H}$ is the combined generator \& turbine inertia constant, $\mathrm{F}$ is combined generator \& turbine friction coefficient.

\section{SVC Model}

The static var compensator has been modeled on the basis of figure shown below. It contains several thyristor switched capacitor branches (TSC) in parallel and thyristor switched reactors (TCR) branches in parallel with TSC branches as shown in fig. 2. Depending upon the requirement of reactive power demand at the point of connection, number of TSC and TCR branches to be switched is decided. A control signal is generated for connecting ad disconnecting the TSC \& TCR branches. The amount of reactive power support at the point of connection in case of SVC depends upon the voltage at the point of connection.

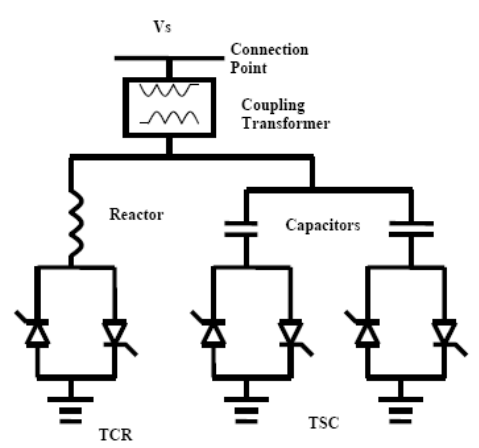

Fig. 2. A static var compensator

\section{STATCOM Model}

A STATCOM contains a voltage source converter with a capacitor connected at the d.c. side and the a.c. side connected with the power system through a coupling transformer. This device is used to regulate the connection point voltage in a a.c. power system by supplying and absorbing reactive power into the system depending upon the requirements. This objective in a STATCOM is accomplished by changing the voltage amplitude at the voltage source converter.

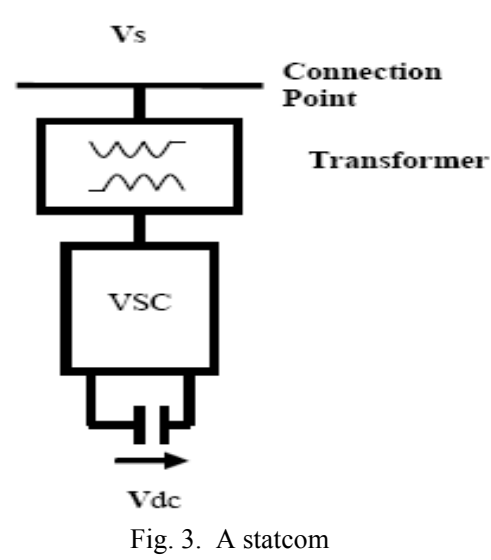

\section{ApProach Used to COMPARE THE ENHANCEMENT OF TRANSIENT Stability Limit By SvC \& Statcom IN THE GIVEN POWER SYSTEM}

In the simulated power system represented in fig.1, a transient condition i.e. a three phase fault was simulated in the power system. For this purpose the $70 \mathrm{~km}$. transmission line which connects the grid with the wind power plant was divided into two parts having the length of $40 \mathrm{~km}$. and $30 \mathrm{~km}$. respectively from bus $\mathrm{B} 1$ to $\mathrm{B} 2$. Bus $\mathrm{B} 2$ is also called the point of common coupling (PCC). In order to compare the performance of the given two fact devices (SVC \& STATCOM) in improving the transient stability margin of the given power system three parameters of the power system were monitored during a three phase fault. These parameters are the voltage and reactive power at the point of common coupling (PCC) and the induction generator rotor speed [10]. A relative comparison of voltage recovery time at $\mathrm{PCC}$ and the damping time period of rotor speed oscillation of the wind generator is performed by the simulation when the power system is supported with FACTS like SVC \& STATCOM of equal converter rating i.e. $5 \mathrm{MVA}$ and finally the results have been interpreted as to which of the FACT device leads to a faster voltage recovery at the PCC and damps the rotor speed oscillations in a relatively lesser time period [10].

\section{RESUltS AND SimULATION}

The first parameter to be monitored is the voltage at PCC. It can be observed from fig. 4 below that prior to the occurrence of fault in the system, the voltage level was 1 p.u. After fault in the system voltage at PCC dipped down to 0.2 p.u. value. The fault recovery was at $3.28 \mathrm{sec}$. But it can be observed from the simulation results that even after the fault recovery, the voltage at PCC did not recover to its pre-fault level of 1 p.u.

Instead there was a voltage collapse at PCC. This is a condition of voltage instability in the system. In order to maintain the voltage stability in the power system we require a device for dynamic reactive power support. A SVC and a STATCOM can serve this purpose. The voltage instability is due to a large reactive power requirement by the wind generator during transient condition like a fault. Fig. 5 shows the voltage at PCC with SVC and STATCOM support. It can 
be observed that soon after the fault recovery, the voltage at PCC catches the pre fault value of 1p.u. From fig 5 it can also be observed that action of STATCOM in maintaining the voltage stability as compared with a SVC is faster. Table I gives the voltage recovery time at $\mathrm{PCC}$ with $\mathrm{SVC}$ and STATCOM connected at PCC.

The second parameter which was monitored during the study is the wind generator-rotor speed. This parameter was assessed in order to determine the generator rotor speed stability and its variation without and with the help of FACT devices support in the power system. The curve in fig. 6 as given below gives the rotor speed of the wind generator without FACTS support. It can be seen that during a three phase fault in the power system with a FSIG wind generator the generator rotor speed increases rapidly and thus it becomes almost impossible to further let the generator remain Connected with the system i.e. with the help of suitable control mechanisms the wind generator is disconnected from the rest of the power system. This situation can be averted if we connect some FACT devices in the power system as can be seen from fig. 7. It can be observed that although the generator rotor speed rises and reaches unstable point, with the connection of fact devices the rotor speed regains its pre-fault (Steady State) value after sometime. If we compare the times of rotor speed recovery with SVC \& STATCOM it is observed that STATCOM is the best in terms of increasing the rotor speed stability.

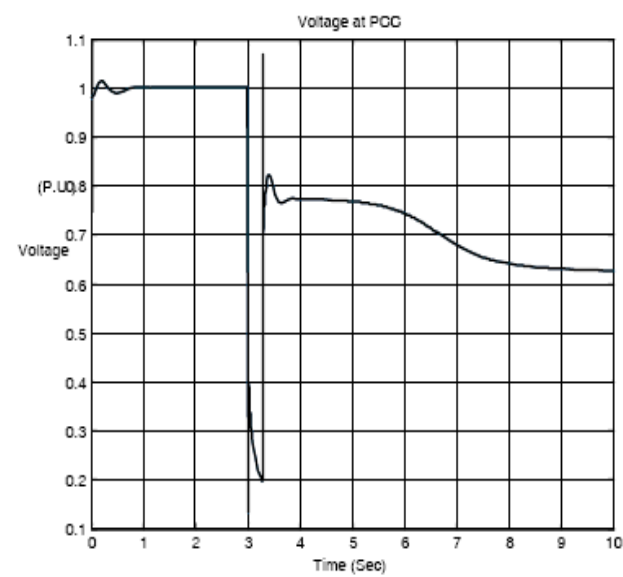

Fig. 4. Voltage at PCC without FACTS.

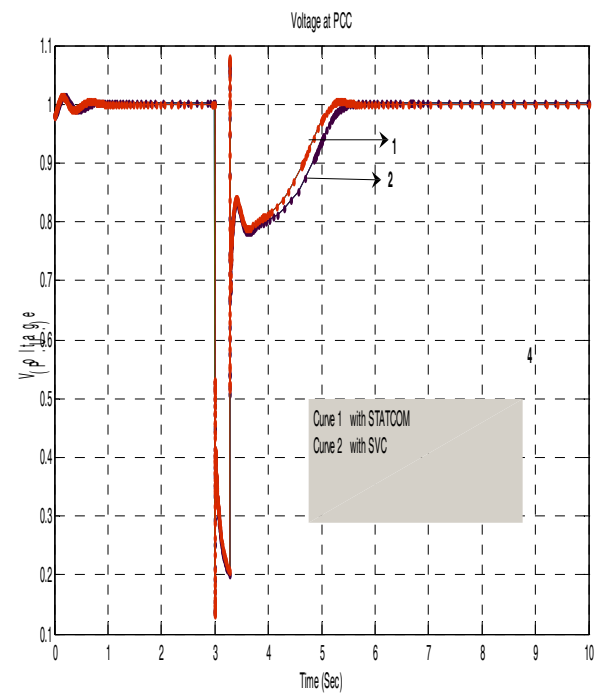

Fig. 5. Voltage at PCC with FACTS.
TABLE I: VOLTAGE RECOVERY TIME AT PCC

\begin{tabular}{|c|c|c|c|}
\hline Fact Devices & $\begin{array}{c}\text { No Fact device } \\
\text { Connected }\end{array}$ & $\begin{array}{c}\text { SVC } \\
\text { (5 MVAR) }\end{array}$ & $\begin{array}{c}\text { STATCOM } \\
\text { (5 MVAR) }\end{array}$ \\
\hline $\begin{array}{c}\text { Voltage Recovery time } \\
\text { At PCC (Sec.) }\end{array}$ & Voltage collapse & 5.35 & 5.224 \\
\hline
\end{tabular}

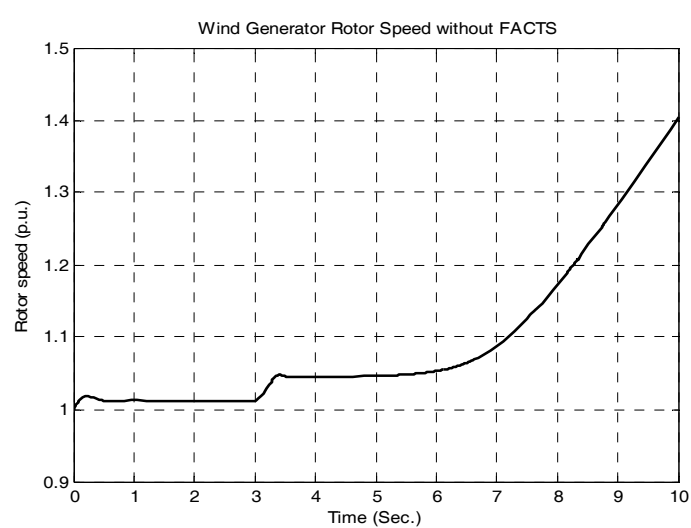

Fig. 6. Generator rotor speed without FACTS

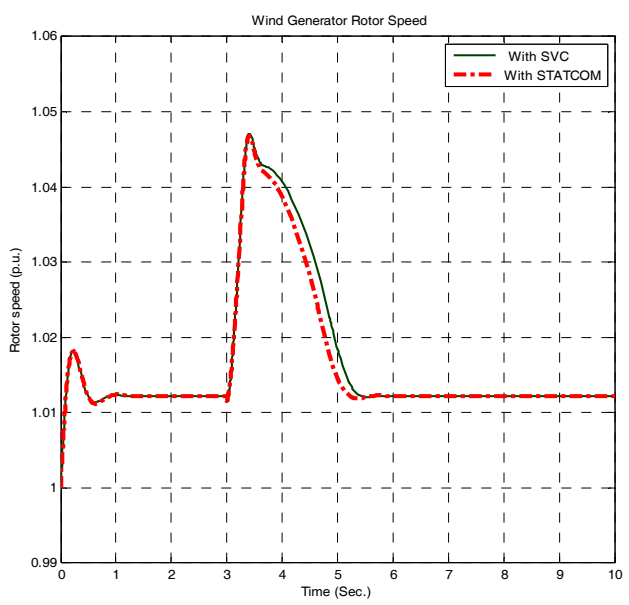

Fig. 7. Generator rotor speed with FACTS.

Table II below gives a comparison of rotor speed recovery time of the generator with and without the FACT devices.

TABLE II: GENERATOR ROTOR SPEED RECOVERY TIME

\begin{tabular}{|c|c|c|c|}
\hline Fact Devices & $\begin{array}{c}\text { No Fact } \\
\text { device } \\
\text { Connected }\end{array}$ & $\begin{array}{c}\text { SVC } \\
\text { (5 } \\
\text { MVAR) }\end{array}$ & $\begin{array}{c}\text { STATCOM } \\
\text { (5 MVAR) }\end{array}$ \\
\hline $\begin{array}{c}\text { Rotor Speed recovery time } \\
\text { (Sec.) }\end{array}$ & Unstable & 5.35 & 5.15 \\
\hline
\end{tabular}

Similar as above parameters we can also compare the reactive power at $\mathrm{PCC}$ in the power system at different conditions. Figure 8 below gives the reactive power at PCC without FACTs support in the power system. It can be observed that the reactive power absorption at PCC after the fault and its recovery suddenly increases to approx. 2 p.u. and never returns to its pre fault value. A relative comparison of the performance of the given two FACT devices show that SVC is slower than the STATCOM in bringing the reactive power to its pre fault value. The recovery time in both the cases is as shown in Table III below.

TABLE III: REACTIVE POWER RECOVERY TIME AT PCC

\begin{tabular}{|l|l|l|}
\hline Fact Devices & $\begin{array}{l}\text { SVC } \\
\text { (5 MVAR) }\end{array}$ & $\begin{array}{l}\text { STATCOM } \\
\text { (5 MVAR) }\end{array}$ \\
\hline Reactive Power (Q) recovery Time (Sec.) & 5.51 & 5.26 \\
\hline
\end{tabular}




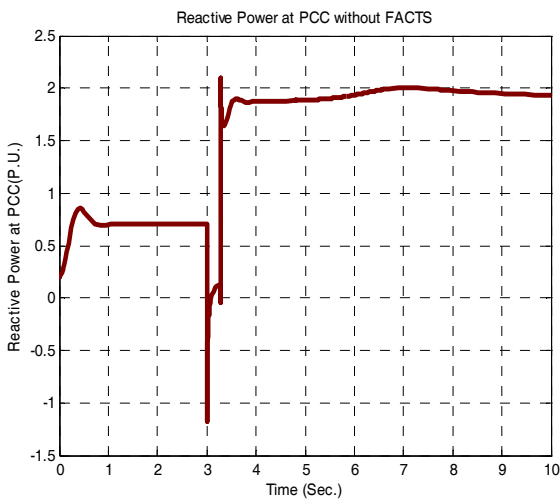

Fig. 9. Reactive powers at PCC without FACTS.

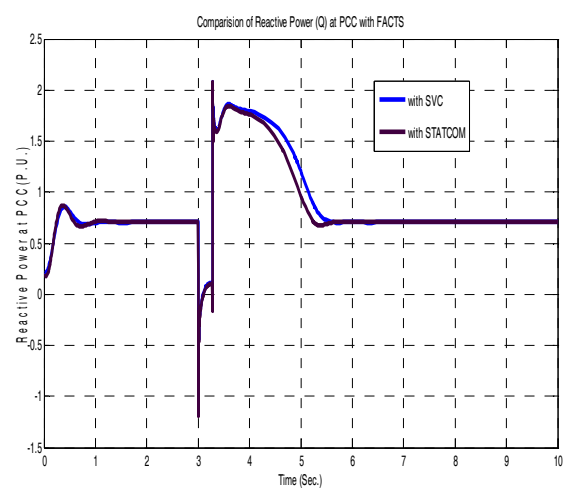

Fig. 9. Reactive powers at PCC with FACTS.

\section{CONCLUSIONS}

FACT devices are power electronics based reactive compensators that are connected in a power system and are capable of improving the power system transient performance and the quality of supply. In this paper system stability of FSIG wind farms has been investigated. The transient performances of a large wind farm equipped with PFC only and equal converter ratings of FACTS like SVC\& STATCOM has been studied for a solid three phase fault at a point on the transmission line connecting the wind farm with the grid. Results of the study show that:

1) During a fault somewhere near FSIG based wind farm in a power system a large amount of reactive power is absorbed by the generator due to sudden increase in the slip, which leads to generator rotor speed instability.

2) The capacitors connected at the wind generator terminals during faults cannot provide sufficient reactive power especially when the wind generator is connected with a weak grid. Hence FACT devices like SVC \& STATCOM can be used to provide dynamic reactive power support leading to improvement in power system stability.

3 ) It can be seen from the results obtained from simulation that if the kvar ratings of both the FACTS (SVC\& STATCOM) is same (5 MVAR in this case), STATCOM is the most effective of them as it is the fastest of the two in improving the system stability.

4) So it can be said on the basis of results obtained that the FACTS like SVC, STATCOM can be used effectively in a power system connected with a wind farm for improving transient stability of wind farms and can become helpful in meeting the grid code requirements for connecting it with the grid.

\section{APPENDIX}

1) Parameters of the wind Generator: Stator resistance $=$ 0.0108 p.u., Rotor resistance $=0.01214$ p.u., Stator leakage inductance $=0.107$ p.u., Rotor leakage inductance $=$ 0.1407 p.u., Mutual inductance $=4.4$ p.u., lumped inertia constant $=3 \mathrm{~S}$.

2) Parameters of SVC: Nominal Voltage $=132 \mathrm{KV}$, Reactive Power limits $=+/-5 \mathrm{MVA}$, Frequency $=50 \mathrm{HZ}, \mathrm{Kp}, \mathrm{Ki}=5$, 1000.

3) Parameters of STATCOM: Nominal Voltage $=132 \mathrm{KV}$, Converter rating $=5 \mathrm{MVA}$, D.C link Nominal Voltage $=$ 10,000, Frequency $=50 \mathrm{HZ}, \mathrm{Kp}, \mathrm{Ki}=5,1000$.

\section{ACKNOWLEDGEMENT}

The author gratefully acknowledges the contributions of Lie Xhu, Liangzhong Yao and Christian Sasse for their contributions \& work in this field.

\section{REFERENCES}

[1] J. G. Slootweg and W. L. Kling, "The impact of large scale winds power generation on power system oscillations," Electric Power System Research, 2003.

[2] P. Jayashri and R. P. Rukmini Devi, "Effect of tuned unified power flow controller to mitigate the rotor speed instability of fixed speed wind turbines," Renewable energy; 34; 2009.

[3] C. Han, Q. Alex Huang, E. Mesut Baran, S. Bhattacharaya, W. Litzenberger, L. Anderson, L. Anders Johnson and Abdel-Aty Edris, "STATCOM impact study on the integration of a large wind farm into a weak loop power system," IEEE Transactions on energy conversion, vol. 23, No. 1, March 2008.

[4] M. Molinas, J. Are Suul and T. Undeland, "Low voltage ride through of wind farms with cage generators: STATCOM vs SVC," IEEE Transactions on power electronics, vol. 23, No. 3, May 2008.

[5] H. Gazatanaga, I. Etxeberria-Otadui, D. Ocnasu, and S. Bacha, "Real-Time analysis of the Transient response improvement of fixed speed wind farms by using a reduced scale STATCOM prototype," IEEE Transactions on power system, vol. 22, No. 2, May 2007.

[6] T. Ackerman, Wind Power in power systems. England: John Wiley and Sons, Ltd. 2005.

[7] C. Chompo-inwai, C. Yingvivatanapong, K. Methaprayoon and W. J. Lee, "Reactive compensation techniques to improve the ride through capability of wind turbine during disturbance," IEEE Transactions on industry applications, vol. 41, No. 3, May 2005.

[8] O. Samuelson and S. Lindahl, "Letters; on speed stability," IEEE Transactions on power system, vol. 20, No. 2, May 2005.

[9] L. Xu, L. Z. Yao and Christian Sasse, "Comparison of using SVC and STATCOM for wind farm integration," IEEE International Conference on Power System Technology, 2006.

[10] G. Mital Kanabar, S. A. Kharpade, "Evaluation of rotor speed stability margin of a constant speed wind turbine generator," IEEE International conference, 2008.

Rajiv Singh is presently working as Assistant Professor in Electrical Engineering Department, College of Technology, G.B. Pant University of Agriculture and Technology, Pantnagar, Uttarakhand, India. He has obtained his B.Tech. degree from NIT Hamirpur (H.P.), India. His M.E. (Control \& Instrumentation) degree is from MNNIT Allahabad, (U.P.). Presently he is pursuing his P.hD. degree from MNNIT Allahabad.

Asheesh Kumar Singh is presently working as Associate Professor in Electrical Engineering Department at MNNIT Allahabad (U.P.). 